\title{
Application of mechanically alloyed MnAl particles to de-colorization of azo dyes
}

Mitra AboliGhasemabadi ${ }^{\mathrm{a}}$, Wael benMbarek ${ }^{\mathrm{b}}$, Oriol Casabella ${ }^{\mathrm{c}}$, Helena Roca-Bisbe ${ }^{\mathrm{c}}$, Eloi

Pineda $^{\mathrm{a}}$, Lluïsa Escoda ${ }^{\mathrm{d}}$, Joan J. Suñol ${ }^{\mathrm{d}}$

${ }^{a}$ Departament de Física, Universitat Politècnica Catalunya - BarcelonaTech, Catalonia, Spain.

${ }^{\text {b} L a b o r a t o i r e ~ d e ~ C h i m i e ~ I n o r g a n i q u e, ~ F a c u l t e ́ ~ d e s ~ S c i e n c e s, ~ U n i v e r s i t e ́ d e ~ S f a x, ~ U r-11-E s-73, ~ T u n i s i e ~}$

${ }^{\mathrm{C} E s c o l a}$ Superior d'Agricultura de Barcelona, Universitat Politècnica Catalunya - BarcelonaTech, Catalonia, Spain.

${ }^{\mathrm{d}}$ Departament de Física, Universitat de Girona, Catalonia, Spain

*Corresponding author:

Mitra AboliGhasemabadi

mitraaboli1985@gmail.com / eloi.pineda@upc.edu

Tel. (34) 615434405

\begin{abstract}
The use of metallic particles has been shown to be an effective, low-cost method for degradation of many contaminating compounds. In this work, we analyze the efficiency of MnAl metallic powders for degrading azo dyes, which are the class of colorant compounds most utilized by the textile industry. We used different routes to produce the metallic particles obtaining different internal structures as characterized by X-ray diffraction and electronic microscopy. The ability to act as discoloration materials was assessed by decolorization experiments of Reactive Black 5 and Orange II azo dyes aqueous solutions. The degradation reaction of the dye molecules was monitored by ultraviolet-visible (UV) spectrophotometry showing fast kinetics, with reaction times among the shortest found in literature. The effect of the different production methods on their performance as decolorizing materials was studied as function as various parameters such as initial $\mathrm{pH}$, dye concentration and temperature. The electrochemical and corrosion properties of the $\mathrm{MnAl}$ compounds seem to be the key factors explaining the high decolorization efficiency of these materials.
\end{abstract}


Keywords: Mechanical alloying, Melt spinning, Decolorization, Orange II, Metallic particles, Zero valent metals

\section{Introduction}

During recent decades, chemical processing industries involved in wet preparing, resizing, scouring, blanching, dyeing, or printing processes have grown considerably in size, resulting in an increased amount of variously colored industrial wastewater being released into the environment. These industrial water effluents, sullied with textile colors, have caused great concern because of their impact on health and their resistance to biodegradation [1]. While textile colorants do differ in substance composition they often exhibit a common component: they are exceptionally stable under normal aerobic conditions. Modern dyes are often designed to resist long exposure to daylight, water, and different conditions, which accordingly makes wastewater containing such dyes more troublesome to treat [2]. This makes it difficult to remove color from wastewater and low concentrations of dying compounds are very visible [3]. Most synthetic industrial dyes possess one or more azo bonds acting as chromophores and connected to various aromatic structures, these azo compounds standout amongst the better known groups of colorants utilized by the textile and leather treatment industries. A critical step during the treatment

of water contaminated by these groups is the degradation of the compounds via the decay of the $-\mathrm{N}=\mathrm{N}$ - bonds resulting in the decolorization of the water [4][5].

Different kinds of physical, chemical, and biological methodologies are applied to the treatment of effluents polluted with azo colorants. Adsorption, biodegradation, coagulation, ozonation, and hypochlorite treatment methodologies have all been broadly used [6][7]. Among these methodologies, color removal using zero-valent metals (ZVM) has been considered as an environmentally friendly solution. This is due to its benefits of easy and quick application, low cost, efficient degradation of azo compounds, its ability to cleave dye molecules into products that are more agreeable to mineralization in biological treatment processes and a simple operation [8][9]. The application method is very simple, the ZVM is put in contact with the dyed solution, acting as a donor of electrons and promoting a reaction leading to the cleavage of the azo bound. The application can be in 
form of particles or other configurations [10], the kinetics of the decolorization reaction being proportional to the total surface of ZVM in contact with the solution [11].

Recently, the use of metastable nanocrystalline and amorphous metals as advanced materials acting as ZVM in water treatment processes has received a lot of attention $[8][9][10][12][13][14][15]$. The aim behind this research effort is to improve the reaction efficiency not by simply increasing the specific surface area but by increasing the reactivity of ZVM material. For example, particles of the same composition but with different internal structure, amorphous or nanocrystalline, showed important differences in their behavior as decolorization materials [10]. Different production routes used in materials science and physical metallurgy to produce metastable compounds, such as mechanical alloying or rapid solidification techniques like melt spinning and gas atomization, have been used to produce advanced decolorizing materials, the production method leading to important changes in the degradation efficiency shown by the materials [8]. Ball milling is a well-known method to synthesize new materials and compounds for a wide range of applications [16][17]. In metallic systems, the high energy introduced during the process is able to produce solid solutions of the metallic elements as well as new metastable phases [18]. Recently, some advanced biocompatible alloys containing Mn have been produced by this method [19].

In this work, Manganese-Aluminum (MnAl) metallic powders were fabricated by different routes, obtaining particles with different inner structure. The study of this compositional system was motivated because of the good performance shown by Mn compounds [20] and Al-based alloys as decolorizing materials [21]. The aim is to compare the influence of the production route and the corresponding inner structure on the decolorization process. The obtained metallic particles were characterized by XRD, EDX and SEM. Afterwards they were applied to decolorization of Reactive Black 5 and Orange II aqueous solutions and the degradation of the dye molecules was monitored by UV-vis spectrophotometry. The degradation and removal of Orange II was studied under many different conditions, thus allowing us to compare the efficiency of the MnAl particles with that of other materials found in literature. Finally, the effect of initial $\mathrm{pH}$, dye concentration, and dosage were investigated. The results show that the inner crystalline phase of the $\mathrm{MnAl}$ particles has not a determinant influence in the reaction kinetics. On the 
other hand, they reveal the prominent role of $\mathrm{Mn}$ as the main reactive element in the dye degradation reaction as well as that the presence of $\mathrm{Al}$ widens the range of conditions in which these materials show high decolorizing efficiency.

\section{Materials and methods}

Two different production routes of $\mathrm{MnAl}$ particles were used, in all cases pure metals of $\mathrm{Mn}$ and $\mathrm{Al}$ with a purity over $99.8 \%$ were utilized as the initial materials. A batch of powder was fabricated by melt-spinning of a master alloy with nominal composition of $\mathrm{Mn}_{70} \mathrm{Al}_{30}$ at.\%, the ribbons obtained by this rapid solidification method were subsequently ball-milled during $15 \mathrm{~h}$. Other batches were fabricated by direct mechanical alloying of elemental Mn and Al powders by milling during 20h, 30h, 60h and 200h. The ball milling process was performed under a highly purified argon atmosphere with a high-intensity shaker ball milling device (SPEX 8000). The milling protocol consisted always in 10 minutes of processing followed by rest periods of 5 minutes, these were applied to prevent the powder from overheating, self-agglomerating or adhering to the container's interior walls or to the milling balls. The microstructure and morphology of the milled powder were characterized by scanning electron microscopy (SEM) and energy dispersive X-ray (EDX) microanalysis using a Hitachi TM3030Plus SEM. The milled powder was verified by X-ray diffraction (XRD) on a Bruker D8 Advance equipment using $\mathrm{Cu}-\mathrm{K}$ radiation to check out the structural changes of the milled powders. Specific surface measurements were performed by means of the Brunauer-Emmett-Teller (BET) model in a Micrometrics ASAP 2020 apparatus using nitrogen as adsorbate and helium as non-adsorbing gas for the dead volume calibration.

The decolorization study was performed on two azo dyes: Reactive Black 5 (RB5) and Orange II sodium salt (both purchased from Sigma-Aldrich). Each experiment was designed to evaluate the effectiveness of $\mathrm{Mn}_{70} \mathrm{Al}_{30}$ particles with regards to the decolorization of the dyed aqueous solutions. The dye solutions were prepared with $40 \mathrm{mg}$ of RB5 or Orange II per liter of water $\left(40 \mathrm{mg} \mathrm{l}^{-1}\right)$. From the prepared dyed solution, $100 \mathrm{ml}$ was extracted and moved to a $250 \mathrm{ml}$ Erlenmeyer glass. Following this, different quantities of powder (from 50 to $250 \mathrm{mg}$ depending on the test) were added and agitated by using 
magnetic stirring at a speed of $500 \mathrm{rpm}$. To investigate the effect of $\mathrm{pH}$, the original dye solutions with $\mathrm{pH}=6.8$ were altered to $\mathrm{pH}=4$ by adding diluted $\mathrm{HCl}$ at $1.0 \mathrm{M}$ and $\mathrm{pH}=10$ by adding diluted $\mathrm{NaOH}$ at $1.0 \mathrm{M}$. The initial $\mathrm{pH}$ changed always towards more basic conditions during the treatments $\left(\mathrm{pH}_{\text {final }}=7.6-7.8\right.$ for initial $\mathrm{pH}=4$ and 7 , and $\mathrm{pH}_{\text {final }}=10.6$ for initial $\mathrm{pH}=10$ ). During the decolorization experiments, $2.5 \mathrm{ml}$ of solution were extracted at regular time intervals and analyzed in a UV/VIS spectrophotometer (2600 Shimadzu). The UV-vis spectra were recorded from 200 to $800 \mathrm{~nm}$ using a quartz cell of $1.0 \mathrm{~cm}$ path length. The concentration of dye was quantified by measuring the absorbance at $\lambda_{\max }=597 \mathrm{~nm}$ (RB5) and $\lambda_{\max }=483 \mathrm{~nm}$ (Orange II), corresponding to the maximum of the absorbance peaks of the colorants. The concentration and absorbance linear relation was assessed by measuring the absorbance spectrum of aqueous solutions of various initial concentrations.

\section{Results and discussion}

The efficiency as dye degradation materials of the MnAl powders was evaluated by decolorizing RB5 and Orange II aqueous solutions. Both Mn and Al have a high value of reduction potential, making them good candidates to act as reducing agents. $\mathrm{Mn}$ and $\mathrm{Al}$ compounds have been used as azo dye degradation materials before [20][21] but the high efficiency of $\mathrm{MnAl}$ compounds was discovered recently [22]. As specified in the materials and methods section, $\mathrm{MnAl}$ powders were obtained by different production routes; namely, melt spinning and subsequent ball milling (MS+BM particles) and direct mechanical alloying of elemental $\mathrm{Mn}$ and $\mathrm{Al}$ powders with different milling times (BM-20h, 30h, 60h and $200 \mathrm{~h}$ particles). All the particles were produced with the same nominal composition of $\mathrm{Mn}_{70} \mathrm{Al}_{30}$. Pure Mn and $\mathrm{Al}$ powders were also used to test the efficiency of these elements as decolorizing materials. In the case pure Mn the decolorization efficiency was tested for both as-purchased powders (Mn-AP) and 30h ball milled Mn (Mn-30h).

Fig. 1 shows the degradation kinetics of RB5 aqueous solutions obtained by MnAl MS+BM, BM-30h and BM-200h particles, as well as pure Mn-AP and Mn-30h. In this work the degradation process is assumed to be described by first-order reaction kinetics following $C(t)=C_{s a t}+\left(C_{0}-C_{s a t}\right) e^{-t / \tau}$, with $C(t)$ the dye concentration, $C_{0}$ the initial concentration, $C_{\text {sat }}$ the final concentration and $\tau$ the rate constant characterizing the speed of 
the reaction. The reactions obtained in this work show $C_{\text {sat }} \sim 0$ indicating a complete decolorization in all cases. The deviations from the exponential decay observed in the initial stays could be attributed to a double step process, as seen in some decolorizing materials [23]. This double step is only observed in the slowest reactions studied in this work and we currently do not know its origins. The description by first order kinetics is however adequate for most of the tests and it allows us to compute easily a reaction time, that characterizes quantitatively the velocity of the reaction.

Despite the completely different internal structure of the particles produced by different fabrication routes, as will be discussed below, both MS+BM and BM particles give a rapid decolorization reaction, among the fastest when compared to other types of metallic alloys found in literature. The first question that arises is if the rapid kinetics come from the chemical properties of the individual $\mathrm{Mn}$ and $\mathrm{Al}$ elements. In order to assess this issue the same decolorization experiments were realized using pure $\mathrm{Mn}$ and $\mathrm{Al}$ powders of similar particle size. As seen in Fig. 1, the use of Mn-AP powder produces a degradation reaction twenty times slower than BM-30h MnAl particles, but Mn-30h achieves much shorter reaction times. On the other hand, the use of pure Al powder did not produce any decolorization effect due to the effect of passivation that prevents the metallic (zero-valent) Al to contact directly with the dyed solution. As will be detailed below, the powders examined by SEM are characterized by broad particle-size distributions and corrugated surfaces. In order to evaluate the effect of the materials' surface reactivity the specific surfaces of Mn-30h and MnAl BM-30h were measured by BET obtaining values of $a_{\mathrm{Mn}}=0.903 \mathrm{~m}^{2} \mathrm{~g}^{-1}$ and $a_{\mathrm{MnAl}}=0.565 \mathrm{~m}^{2} \mathrm{~g}^{-1}$ respectively. Considering a reaction proportional to the amount of surface, as expected in decolorizing reactions by ZVM [11], the reaction time $\tau$ multiplied by the specific surface $a$, gives a measure of the reactivity of the materials' surface. As seen from the obtained values, although Mn shows an inherent high ability for azo dye degradation, as already reported by other Mn compounds [20], the combination with $\mathrm{Al}$ favors in some way the decolorization efficiency.

In order to adequately compare the performance of $\mathrm{MnAl}$ particles with that of other decolorizing materials, in addition to RB5, Orange II dye was chosen for this study. Orange II dyed solutions have been used in many works assessing the efficiency of advanced decolorizing materials [4][5][11][13] and it is maybe the colorant most used in studies of 
color removal by means ZVM particles. It is then a kind of benchmark compound, perfect to put in context our results comparing the efficiency of the MnAl particles with that of other materials. Fig. 2 shows the reaction kinetics of degradation of Orange II by BM particles produced by different ball-milling times. Recently, Qin et al. [7] found ultrafast degradation of Orange II aqueous solutions adding $120 \mathrm{mg}$ of $\mathrm{Co}_{78} \mathrm{Si}_{8} \mathrm{~B}_{14}$ metallic glass particles in $120 \mathrm{ml}$ solution of $40 \mathrm{mg} \mathrm{l}^{-1}$ of dye concentration. They obtained a reaction rate of less than $1 \mathrm{~min}$, which is the fastest ever found in this kind of studies. Here we used 100 $\mathrm{mg}$ of particles in $100 \mathrm{ml}$ of dye solution of the same concentration obtaining a reaction rate of $\sim 5$ min for the BM particles milled during 60h, this is similar to $\mathrm{MgZn} \mathrm{[9]} \mathrm{and} \mathrm{Fe-based}$ [10][13] metallic glass particles and hundreds of times faster than commercial zero-valent $\mathrm{Fe}$ [11][24]. The results on Orange II confirm that MnAl particles are among the group of advanced materials showing the fastest kinetics of degradation of azo compounds at room temperature conditions.

The second question to answer is what is the effect of the internal structure of the particles on their decolorization efficiency. Fig. 3 shows the X-ray diffraction patterns of the MnAl particles, revealing important differences in internal structure depending on the production route. $\mathrm{MS}+\mathrm{BM}$ particles are composed of a unique $\beta$-Mn phase, which accepts up to 40 at.\% of aluminum in solid solution in equilibrium. On the other hand, the BM particles are composed of two phases, a rich Mn phase ( $\alpha$-Mn accepting up to 5 at.\% of Al in solid solution in equilibrium) and fcc Al. No significant differences in terms of phase identification were found between different milling times of the different types of BM powders produced, all were found to be composed by $\alpha$-Mn and fcc Al and the degree of alloying of $\mathrm{Al}$ inside the Mn-rich phase was not possible to assess quantitatively. DebyeScherrer analysis of the width of the Bragg peaks gives an average internal grain size of $70 \pm 20 \mathrm{~nm}$ with not statistically significant differences between MS+BM, BM-30h and BM$60 \mathrm{~h}$ particles.

The morphologies and composition of the $\mathrm{Mn}_{70} \mathrm{Al}_{30}$ powders were examined by SEM and EDX microanalysis. The particles surface shows a corrugated aspect typical of powders obtained by mechanical alloying, this favors the efficiency as decolorization materials as discussed in ref. [8]. The size distribution of the powder is very wide and the average 
diameter is estimated to be between 2 and $50 \mu \mathrm{m}$ in the case of powders milled for $30 \mathrm{~h}$ or more. Fig. 4 shows a compositional map of a BM-30h particle obtained by EDX. The analysis of the SEM images show that the BM powders are formed by particles composed of Mn-rich and Al-rich zones. Therefore, the powders obtained by direct mechanical alloying are composed by multiphase particles composed of $\mathrm{Al}$ rich and $\mathrm{Mn}$ rich grains. While the particles size is of the order of micrometers, their inner microstructure is composed of crystalline grains below 100 nanometers as confirmed by the Debye-Scherrer analysis of the XRD patterns mentioned above. On the other hand, the powders produced by melt spinning and subsequent ball milling are composed of particles with homogenous composition and a single crystalline phase. However, the morphology of the particles and the size of the crystalline grains inside the particles is similar in both cases.

In view of the above results, the high decolorization ability of the MnAl particles is not a consequence of a particular intermetallic phase as the efficiency of $\beta-\mathrm{Mn}$ and $\alpha-$ $\mathrm{Mn}+\mathrm{Al}$ particles is not significantly different. On the other hand, the results suggest that the decolorization ability is a consequence of the particular electrochemical properties of the Mn-Al pair once the two elements are sufficiently mixed, independently if this is being achieved by melting or by mechanical alloying. In the latter case this is only achieved by milling times equal or longer than $30 \mathrm{~h}$. The exceptional decolorizing efficiency of the $\mathrm{MnAl}$ particles may be originated because the inherent decolorizing ability shown by pure $\mathrm{Mn}$ is somehow potentiated by the presence of $\mathrm{Al}$ or, alternatively, because $\mathrm{Al}$ atoms contribute actively to the degradation reaction if sufficiently alloyed with other elements. The active role of $\mathrm{Al}$ in the degradation reaction was proposed in a previous work [22]. Furthermore, Wang et al. [21] showed recently that Al-Ni crystalline alloys and Al-Ni-Y amorphous alloys were able to activate a fast degradation reaction of azo dyes, with the formation of $\mathrm{Al}(\mathrm{OH})_{3}$ being the key step in the reaction. They found a progressive and rather slow release of aluminum hydroxide in the water, resulting in a continuous corrosion process of the particles that maintains their activity as decolorizing materials during a long time. In the present study, a similar role of $\mathrm{Al}$ atoms in the reaction could be possible, thus potentiating the decolorizing ability of the material.

The effect of dosage, $\mathrm{pH}$ and temperature was assessed by decolorizing experiments of Orange II solutions by MnAl BM-30h particles. Experiments were completed in a 
temperature range of $25-50{ }^{\circ} \mathrm{C}$ to monitor the temperature impact on the decolorization process. Fig. 5 shows the effect of temperature on the kinetics and the Arrhenius plot of the obtained time constants showing an activation energy of $49 \pm 5 \mathrm{~kJ} \mathrm{~mol}^{-1}$. Values of activation energy between 30 and $80 \mathrm{~kJ} \mathrm{ml}^{-1}$ have been found for the decolorizing reactions of different azo-colorants by metallic particles [3][8][9]. In the particular case of Orange II, the activation energy was found $28 \mathrm{~kJ} \mathrm{~mol}^{-1}$ for Fe-based [10] and $33 \mathrm{~kJ} \mathrm{~mol}^{-1}$ for Co-based [7] metallic glasses. Activation energies of 28 to $50 \mathrm{~kJ} \mathrm{~mol}^{-1}$ were found for degradation reactions combining $\mathrm{MnFe}_{2} \mathrm{O}_{4}$ or $\mathrm{CoFe}_{2} \mathrm{O}_{4}$ acting as catalysts with peroxymonosulfate or hydrogen peroxide concentrations [4].

The study was also conducted with different dosages of BM-30h particles, namely 30, $50,100 \mathrm{mg}$ and $250 \mathrm{mg}$, finding the expected proportional increase of velocity as function of metal-solution contact surface area but without differences in the activation energy. The reaction times $\tau$ normalized by the dosage of particles $m\left(\mathrm{~g} \mathrm{~L}^{-1}\right)$ and the Orange II concentration $C_{0}(\mathrm{~g} / \mathrm{L}), \tau m / C_{0}$, are found to be from 2 to 5 times shorter than the ones obtained with micro-particles of Zero-Valent Iron [24]. This may be attributed to a higher reactivity, a larger specific surface or to a combination of both factors. Furthermore, the proportionality between the reaction velocity and the dosage confirmed the first order reaction kinetics expected for a decolorization reaction based on the cleavage of the azo bound by ZVM particles acting as reducing agent. The cleavage of the azo bound of the RB5 and Orange II molecules as the main mechanism of the decolorizing reaction was also confirmed by high-performance liquid chromatography.

More interestingly, and contrary to the behavior commonly found for other advanced decolorizing materials, the effect of $\mathrm{pH}$ was found very small. The reaction of Orange II degradation by BM-30h particles was studied changing the initial $\mathrm{pH}$ from 4 to 10 , and the characteristic time of the reaction did not change significantly. All the characteristic times fitted from the different replicates of the experiments were found within the range $\tau=8 \pm 3$ min, maintaining the fast kinetics both in acidic and alkaline conditions and not showing a statistically significant tendency of increasing the efficiency or the kinetics of the reaction as function of initial $\mathrm{pH}$. Generally, ZVM particles show improved degradation velocities and efficiencies in acidic solutions and an inhibition of the reaction in alkaline conditions. 
This is not the case in the MnAl materials studied in this work. Both $\mathrm{Al}$ and $\mathrm{Mn}$ ions have different solubility dependent on the $\mathrm{pH}$ conditions. In aqueous media, Al oxidizes for $\mathrm{pH}<3$ but it forms $\mathrm{Al}(\mathrm{OH}) 3$ for $\mathrm{pH}>5$. On the other hand, $\mathrm{Mn}^{2+}$ forms soluble salts at $\mathrm{pH}<3$ but its solubility decreases with increasing $\mathrm{pH}$ until becoming completely insoluble at $\mathrm{pH}=9$. ICP-MS measurements of the aqueous solutions after the degradation processes with initial $\mathrm{pH}=4$ conditions show concentrations of ions $\left[\mathrm{Mn}^{2+}\right]=23804 \mathrm{ppb}$ and $\left[\mathrm{Al}^{3+}\right]=290 \mathrm{ppb}$ confirming this difference in solubility. It is expected that the oxidation and dissolution of Mn permits that non-oxidized $\mathrm{Al}$ atoms, originally inside the metallic matrix, become exposed to the dyed solution thus participating also in the redox process in acidic conditions. Therefore, in acidic conditions the mechanism proposed for the degradation of Orange II is the same as the one proposed in ref. [22] for RB5 degradation:

$$
\begin{aligned}
& A l \rightarrow \mathrm{Al}^{3+}+3 e^{-} \\
& \mathrm{Mn} \rightarrow \mathrm{Mn}^{2+}+2 e^{-} \\
& 2 \mathrm{H}_{2} \mathrm{O} \longrightarrow \mathrm{H}_{3} \mathrm{O}^{+}+\mathrm{OH}^{-} \\
& 2 \mathrm{H}_{3} \mathrm{O}^{+}+2 e^{-} \longrightarrow \mathrm{H}_{2}+2 \mathrm{H}_{2} \mathrm{O} \\
& \mathrm{Al}^{3+}+3 \mathrm{OH}{ }^{-} \longrightarrow \mathrm{Al}(\mathrm{OH})_{3} \\
& \mathrm{R}-\mathrm{N}=\mathrm{N}-\mathrm{R}^{\prime}+\mathrm{H}_{2} \longrightarrow \mathrm{R}-\mathrm{NH}-\mathrm{NH}-\mathrm{R}^{\prime} \\
& \mathrm{R}-\mathrm{NH}-\mathrm{NH}-\mathrm{R}^{\prime}+\mathrm{H}_{2} \longrightarrow \mathrm{R}-\mathrm{NH}_{2}+\mathrm{R}^{\prime}-\mathrm{NH}_{2}
\end{aligned}
$$

On the other hand, at high $\mathrm{pH}$ Mn form insoluble hydroxides while the Al hydroxides become soluble, this becoming the main mechanism of the particles degradation reaction. In basic conditions we propose the following mechanisms:

$$
\begin{aligned}
& \mathrm{Al} \rightarrow \mathrm{Al}^{3+}+3 e^{-} \\
& 2 \mathrm{H}_{2} \mathrm{O}+2 e^{-} \longrightarrow \mathrm{H}_{2}+2 \mathrm{OH}^{-} \\
& \mathrm{Al}^{3+}+3 \mathrm{OH}^{-} \longrightarrow \mathrm{Al}(\mathrm{OH})_{3}+\mathrm{OH}^{-} \longrightarrow\left[\mathrm{Al}(\mathrm{OH})_{4}\right]^{-} \\
& \mathrm{Mn} \rightarrow \mathrm{Mn}^{2+}+2 e^{-} \\
& \mathrm{Mn}^{2+}+2 \mathrm{OH}^{-} \longrightarrow \mathrm{Mn}(\mathrm{OH})_{2} \\
& \mathrm{R}-\mathrm{N}=\mathrm{N}-\mathrm{R}^{\prime}+\mathrm{H}_{2} \longrightarrow \mathrm{R}-\mathrm{NH}-\mathrm{NH}-\mathrm{R}^{\prime} \\
& \mathrm{R}-\mathrm{NH}-\mathrm{NH}-\mathrm{R}^{\prime}+\mathrm{H}_{2} \longrightarrow \mathrm{R}-\mathrm{NH}_{2}+\mathrm{R}^{\prime}-\mathrm{NH}_{2}
\end{aligned}
$$

In other studies, Al-based alloys in metastable form showed good performance in alkaline conditions [21], the good performance under a wide range of $\mathrm{pH}$ is then a possible 
indication of the active role of $\mathrm{Al}$ in the reaction. At this point, however, the proposed mechanism of the reaction needs further experimental confirmation.

Summarizing the results above, the high decolorizing efficiency of metallic MnAl particles can be mainly attributed to the role of the Mn element. However, Al addition is shown to change the efficiency depending on the colorant type, $\mathrm{pH}$ and, possibly, other conditions of the aqueous solutions. The determination of the exact mechanism responsible of the fast degradation reaction, the recyclability and durability of the MnAl powders under different application conditions, as well as the amount of release of Mn ions and other products of the reaction in the water are various of the crucial aspects still unknown for this material. They are current under investigation in order to assess the real applicability of $\mathrm{MnAl}$ particles in water remediation processes.

\section{Conclusions}

MnAl particles were produced by different routes. The particles produced by meltspinning and subsequent ball milling were composed by a single homogenous $\beta-\mathrm{Mn}(\mathrm{Al})$ phase. The particles produced directly by mechanical alloying were heterogeneously composed of Mn-rich and Al-rich crystalline phases. Despite the difference in crystalline structure, both particles showed an outstanding performance as decolorizing materials of azo dyes aqueous solutions. The inherent ability of Mn as decolorizing agent is potentiated by the presence of $\mathrm{Al}$, obtaining a degradation efficiency among the highest found in literature. Contrary to Fe-based materials, the high decolorizing efficiency is not decreased in alkaline conditions. This being of importance for the application of this material in real wastewater treatments. The easy production method and the high performance shown by MnAl particles makes them worth to be considered as promising materials for environmental remediation.

\section{Acknowledgments}


Authors acknowledge financial support from MINECO (grant FIS2014-54734-P), from UdG (grant MPCUdG2016-045) and Generalitat de Catalunya (grant 2014SGR00581).

\section{References}

[1] N.K. Amin, Removal of direct blue-106 dye from aqueous solution using new activated carbons developed from pomegranate peel: Adsorption equilibrium and kinetics, J. Hazard. Mater. 165 (2009) 52-62. doi:10.1016/j.jhazmat.2008.09.067.

[2] Gergo Mezohegyi, Alexey Kolodkin, Ursula I. Castro, Christophe Bengoa, Frank Stuber, and Josep Font, A. Fabregat*, A. Fortuny, Effective Anaerobic Decolorization of Azo Dye Acid Orange 7 in Continuous Upflow Packed-Bed Reactor Using Biological Activated Carbon System, (2007). doi:10.1021/IE061692O.

[3] J. Fan, Y. Guo, J. Wang, M. Fan, Rapid decolorization of azo dye methyl orange in aqueous solution by nanoscale zerovalent iron particles, J. Hazard. Mater. 166 (2009) 904-910. doi:10.1016/j.jhazmat.2008.11.091.

[4] J. Deng, S. Feng, X. Ma, C. Tan, H. Wang, S. Zhou, T. Zhang, J. Li, Heterogeneous degradation of Orange II with peroxymonosulfate activated by ordered mesoporous MnFe2O4, Sep. Purif. Technol. $167 \quad$ (2016) 181-189. doi:10.1016/j.seppur.2016.04.035.

[5] X. Guo, H. Li, S. Zhao, Fast degradation of Acid Orange II by bicarbonate-activated hydrogen peroxide with a magnetic S-modified $\mathrm{CoFe} 2 \mathrm{O} 4$ catalyst, J. Taiwan Inst. Chem. Eng. 55 (2015) 90-100. doi:10.1016/j.jtice.2015.03.039.

[6] T.A. Khan, S. Dahiya, I. Ali, Use of kaolinite as adsorbent: Equilibrium, dynamics and thermodynamic studies on the adsorption of Rhodamine B from aqueous solution, Appl. Clay Sci. 69 (2012) 58-66. doi:10.1016/j.clay.2012.09.001.

[7] X.D. Qin, Z.W. Zhu, G. Liu, H.M. Fu, H.W. Zhang, A.M. Wang, H. Li, H.F. Zhang, Ultrafast degradation of azo dyes catalyzed by cobalt-based metallic glass, Sci. Rep. 5 (2015) 18226. http://dx.doi.org/10.1038/srep18226.

[8] J.-Q. Wang, Y.-H. Liu, M.-W. Chen, G.-Q. Xie, D. V. Louzguine-Luzgin, A. Inoue, J.H. Perepezko, Rapid Degradation of Azo Dye by Fe-Based Metallic Glass Powder, Adv. Funct. Mater. 22 (2012) 2567-2570. doi:10.1002/adfm.201103015.

[9] J.-Q. Wang, Y.-H. Liu, M.-W. Chen, D. V Louzguine-Luzgin, A. Inoue, J.H. Perepezko, Excellent capability in degrading azo dyes by MgZn-based metallic glass powders, Sci. Rep. 2 (2012) 418. doi:10.1038/srep00418.

[10] C. Zhang, Z. Zhu, H. Zhang, Z. Hu, On the decolorization property of Fe-Mo-Si-B alloys with different structures, J. Non. Cryst. Solids. 358 (2012) 61-64. doi:10.1016/j.jnoncrysol.2011.08.023. 
[11] J. Cao, L. Wei, Q. Huang, L. Wang, S. Han, Reducing degradation of azo dye by zero-valent iron in aqueous solution, Chemosphere. 38 (1999) 565-571. doi:10.1016/S0045-6535(98)00201-X.

[12] C. Zhang, H. Zhang, M. Lv, Z. Hu, Decolorization of azo dye solution by Fe-MoSi-B amorphous alloy, J. Non. Cryst. Solids. 356 (2010) 1703-1706. doi:10.1016/j.jnoncrysol.2010.06.019.

[13] C. Zhang, Z. Zhu, H. Zhang, Z. Hu, Rapid decolorization of Acid Orange II aqueous solution by amorphous zero-valent iron, J. Environ. Sci. 24 (2012) 1021-1026. doi:10.1016/S1001-0742(11)60894-2.

[14] X. Luo, R. Li, J. Zong, Y. Zhang, H. Li, T. Zhang, Enhanced degradation of azo dye by nanoporous-copper-decorated $\mathrm{Mg}-\mathrm{Cu}-\mathrm{Y}$ metallic glass powder through dealloying pretreatment, Appl. Surf. Sci. 305 (2014) 314-320. doi:10.1016/j.apsusc.2014.03.069.

[15] Y.F. Zhao, J.J. Si, J.G. Song, Q. Yang, X.D. Hui, Synthesis of Mg-Zn-Ca metallic glasses by gas-atomization and their excellent capability in degrading azo dyes, Mater. Sci. Eng. B. 181 (2014) 46-55. doi:10.1016/j.mseb.2013.11.019.

[16] A. Stolle, T. Szuppa, S.E.S. Leonhardt, B. Ondruschka, Ball milling in organic synthesis: solutions and challenges, Chem. Soc. Rev. 40 (2011) 2317. doi: $10.1039 / \mathrm{c} 0 \mathrm{cs} 00195 \mathrm{c}$.

[17] H. Lyu, B. Gao, F. He, C. Ding, J. Tang, J.C. Crittenden, Ball-Milled Carbon Nanomaterials for Energy and Environmental Applications, ACS Sustain. Chem. Eng. 5 (2017) 9568-9585. doi:10.1021/acssuschemeng.7b02170.

[18] C. Suryanarayana, Mechanical alloying and milling, Prog. Mater. Sci. 46 (2001) 1184. doi:10.1016/S0079-6425(99)00010-9.

[19] Y.P. Feng, N. Gaztelumendi, J. Fornell, H.Y. Zhang, P. Solsona, M.D. Baró, S. Suriñach, E. Ibáñez, L. Barrios, E. Pellicer, C. Nogués, J. Sort, Mechanical properties, corrosion performance and cell viability studies on newly developed porous Fe-Mn-Si-Pd alloys, J. Alloys Compd. 724 (2017) 1046-1056. doi:10.1016/J.JALLCOM.2017.07.112.

[20] C.E. Clarke, F. Kielar, H.M. Talbot, K.L. Johnson, Oxidative Decolorization of Acid Azo Dyes by a Mn Oxide Containing Waste, Environ. Sci. Technol. 44 (2010) 11161122. doi:10.1021/es902305e.

[21] P. Wang, J.-Q. Wang, H. Li, H. Yang, J. Huo, J. Wang, C. Chang, X. Wang, R.-W. $\mathrm{Li}$, G. Wang, Fast decolorization of azo dyes in both alkaline and acidic solutions by Al-based metallic glasses, J. Alloys Compd. 701 (2017) 759-767. doi:10.1016/j.jallcom.2017.01.168.

[22] W. Ben Mbarek, M. Azabou, E. Pineda, N. Fiol, L. Escoda, J.J. Suñol, M. Khitouni, H.F. Zhang, Rapid degradation of azo-dye using Mn-Al powders produced by ballmilling, RSC Adv. 7 (2017) 12620-12628. doi:10.1039/C6RA28578C.

[23] M. Stylidi, D.I. Kondarides, X.E. Verykios, Mechanistic and kinetic study of solarlight induced photocatalytic degradation of Acid Orange 7 in aqueous TiO 2 suspensions, Int. J. Photoenergy. 5 (2003) 59-67. 
doi:10.1155/S1110662X0300014X.

[24] S. Nam, P.G. Tratnyek, Reduction of azo dyes with zero-valent iron, Water Res. 34 (2000) 1837-1845. doi:10.1016/S0043-1354(99)00331-0. 


\section{Figure Captions}

Figure 1. RB5 decolorization reaction of pure Mn-AP particles (black filled symbols), Mn30h (black open symbols), MS+BM (blue symbols), BM-30h (red symbols) and BM-200h (green symbols). Solid lines are fittings to a first order reaction kinetics with $\tau_{\mathrm{MS}+\mathrm{BM}}=3.7$ $\min , \tau_{\mathrm{BM}-30 \mathrm{~h}}=1.8 \mathrm{~min}, \tau_{\mathrm{BM}-200 \mathrm{~h}}=6.0 \mathrm{~min}, \tau_{\mathrm{Mn}-30 \mathrm{~h}}=9.5 \mathrm{~min}, \tau_{\mathrm{Mn}-\mathrm{AP}}=40 \mathrm{~min}\left(\mathrm{R}^{2}\right.$ values higher than 0.9 but in the case of pure $M n$ where $\left.\mathrm{R}^{2}=0.5-0.6\right)$. Inset: Evolution of the absorbance spectrum of RB5 solutions during the decolorization process.

Figure 2. Decolorization reaction of BM-20h particles (yellow symbols), BM-30h particles (orange symbols) and BM-60h particles (blue symbols). Solid lines are fittings to a first order reaction kinetics with $\tau_{\mathrm{BM}-20 \mathrm{~h}}=80 \mathrm{~min}, \tau_{\mathrm{BM}-30 \mathrm{~h}}=11 \mathrm{~min}, \tau_{\mathrm{BM}-60 \mathrm{~h}}=5.5 \mathrm{~min}\left(\mathrm{R}^{2}\right.$ values higher than 0.9 in all cases). Inset: Evolution of the absorbance spectrum of Orange II solutions during the decolorization process.

Figure 3. XRD diffraction patterns of BM-30h particles (top) and MS+BM particles (bottom). Top pattern corresponds to $\alpha-\mathrm{Mn}(I \overline{4} 3 m)$ and fcc aluminum phases, the Bragg peaks of the latter phase specified. Bottom pattern corresponds to $\beta$ - Mn $\left(P 4_{1} 32\right)$ phase.

Figure 4. SEM image of BM-30h particles and an example of inner compositional map of a selected particle.

Figure 5. Degradation reaction of Orange II dyed solutions by BM-30h powders at $25{ }^{\circ} \mathrm{C}$ (blue), $30{ }^{\circ} \mathrm{C}$ (green), $35{ }^{\circ} \mathrm{C}$ (yellow), $40{ }^{\circ} \mathrm{C}$ (orange) and $45{ }^{\circ} \mathrm{C}$ (red). Inset: Arrhenius plot of the characteristic times of the reactions. 
Highlights

1. High decolorization efficiency of metallic particles for different azo dyes

2. Mn-Al particles are advanced metallic materials for degradation of azo compounds

3. Outstanding fast decolorization ability associated to $\mathrm{Mn}-\mathrm{Al}$ chemical properties

4. Easy production method by mechanical alloying 


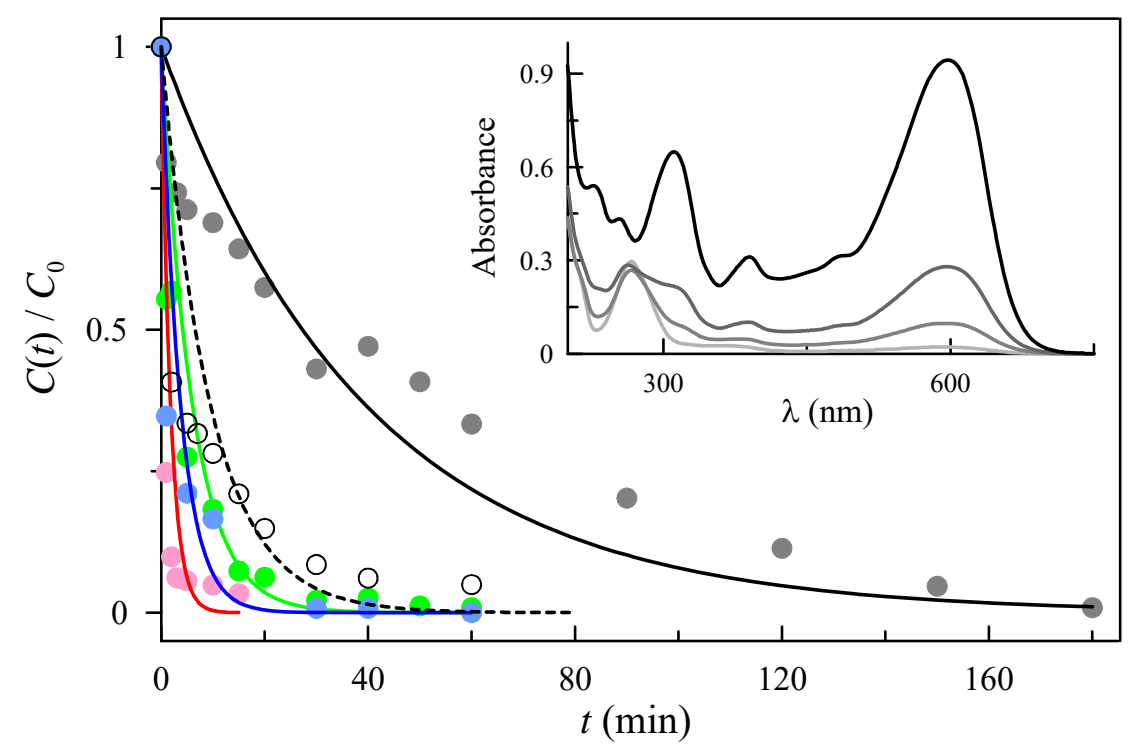




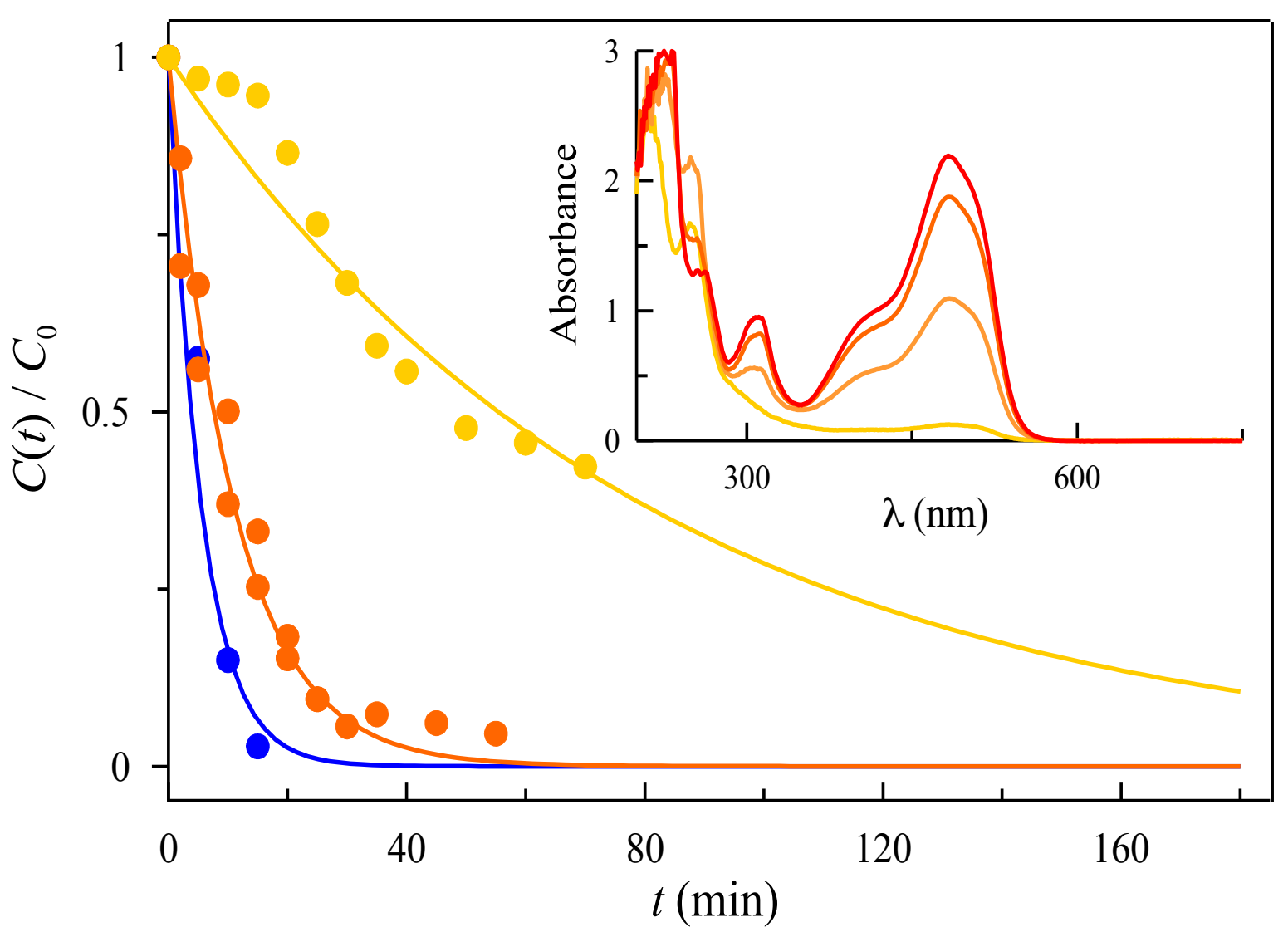




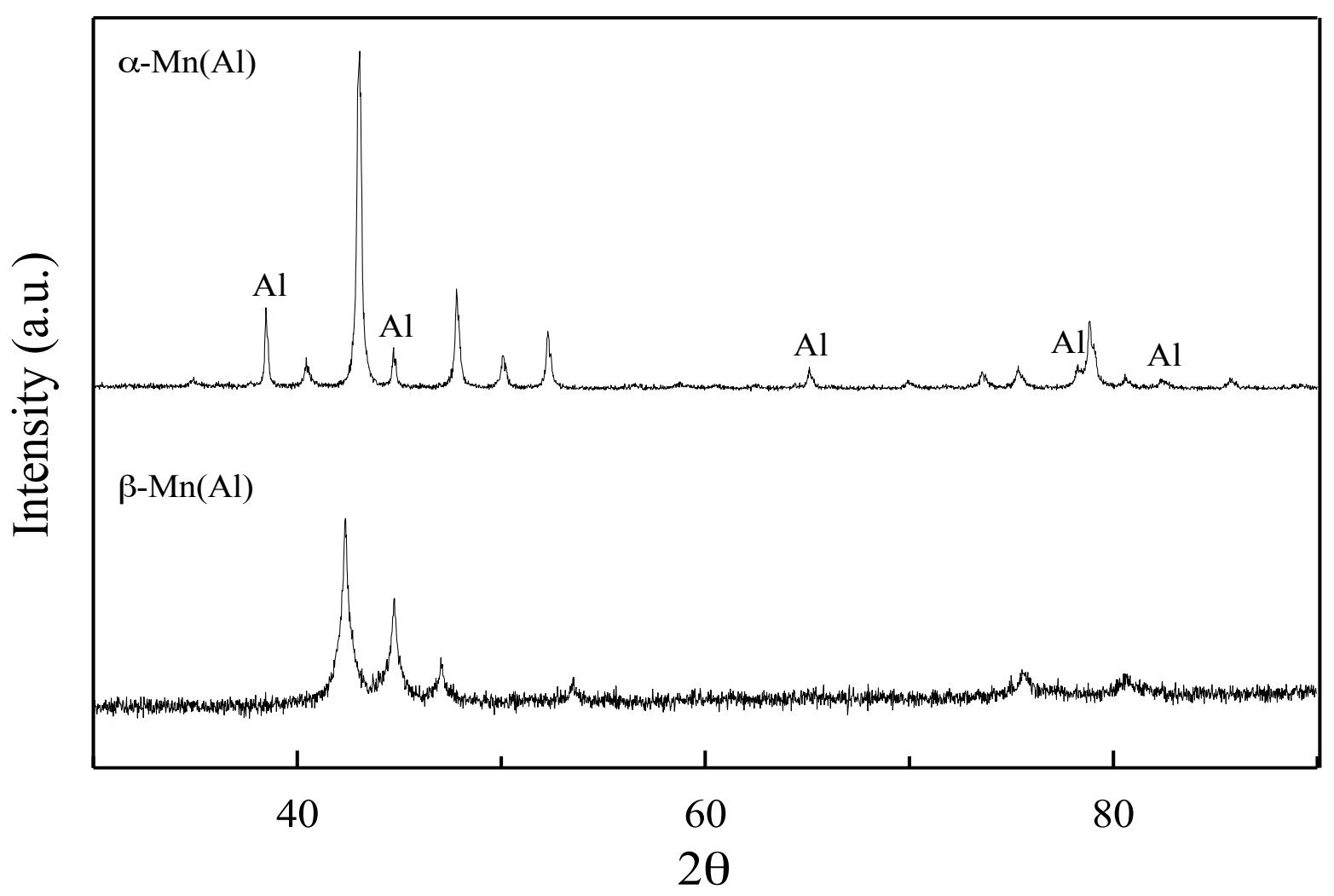




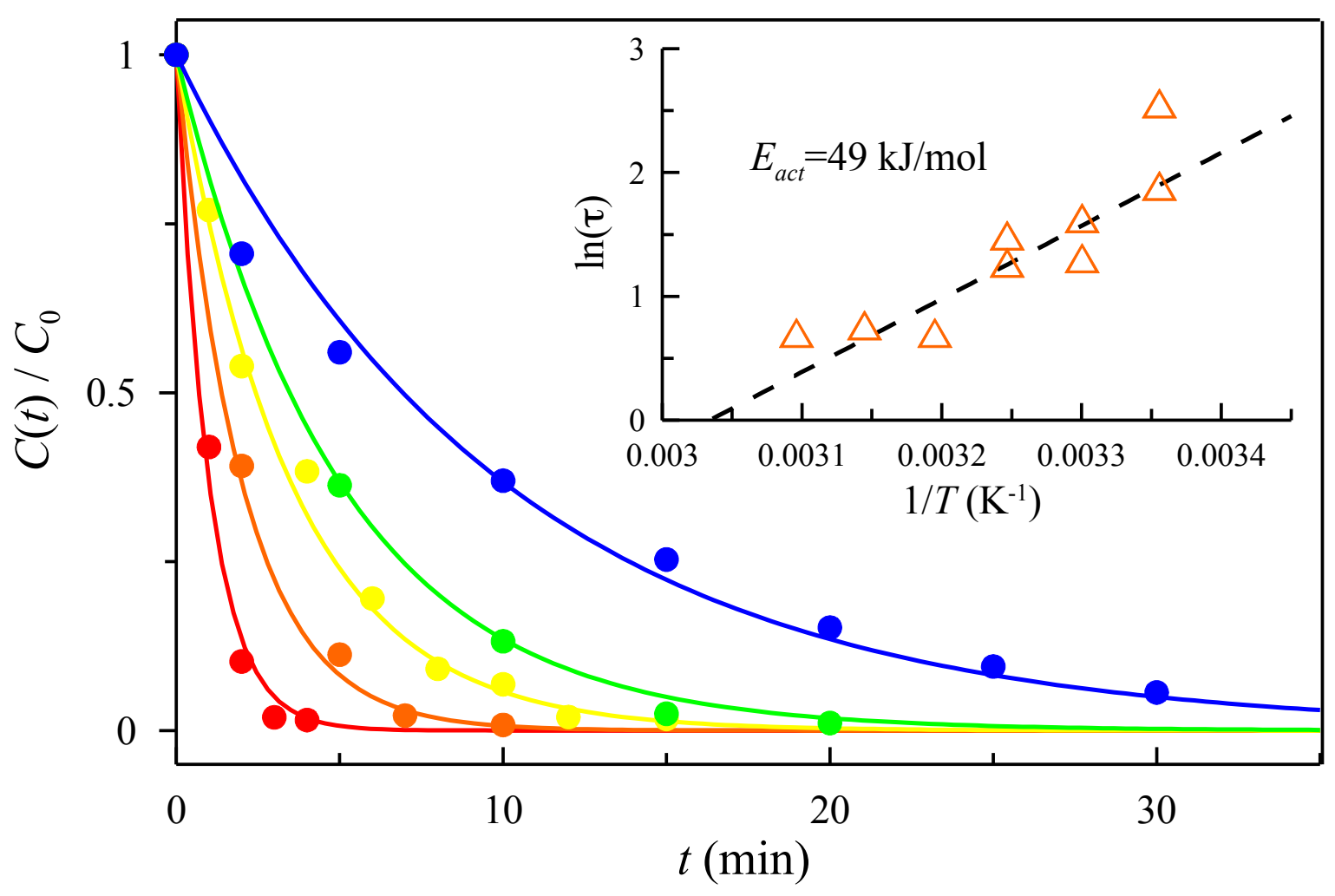

